\title{
Correction to: Leveraging cloud computing for the semantic web: review and trends
}

\author{
Oluwasegun Adedugbe ${ }^{1} \cdot$ Elhadj Benkhelifa $^{1}$ (D) $\cdot$ Russell Campion $^{1} \cdot$ Feras Al-Obeidat $^{2} \cdot$ Anoud Bani Hani $^{2}$. \\ Uchitha Jayawickrama ${ }^{3}$
}

Published online: 5 March 2020

(C) Springer-Verlag GmbH Germany, part of Springer Nature 2020

\section{Correction to: Soft Computing}

https://doi.org/10.1007/s00500-019-04559-2

Unfortunately, the given names and the family name of the author Uchitha Jayawickrama incorrectly published in the original article.

The correct names should read as follows:

Uchitha Jayawickrama

The original article has been corrected.

Publisher's Note Springer Nature remains neutral with regard to jurisdictional claims in published maps and institutional affiliations.

The original article can be found online at https:// doi.org/10.1007/s00500-019-04559-2.

Oluwasegun Adedugbe

Oluwasegun.adedugbe@research.staffs.ac.uk

1 School of Computing and Digital Technologies, Staffordshire University, Stoke-on-Trent, UK

2 College of Technological Innovation, Zayed University, Dubai, UAE

3 School of Business and Economics, Loughborough University, Loughborough, UK 